December 22, 1942, I found that the fundi were normal, and on July 1 the fundus pictures shewn in the drawings were fully developed. This all speaks for some rapid mechanical act, and does not suggest a slow pathological process such as the formation of new vessels.

I shall present the original coloured drawings to the Nuffield Ophthalmic Institution where they will doubtless be open to inspection. This Institution also houses the-original drawings made by Robert Doyne of the original case he described in 1889 .

\title{
AN OPERATION FOR SHRUNKEN SOCKET
}

\section{BY \\ DR. J. KRAUS}

SHRUNKEN socket is a frequent aftermath of war injuries of the eye. Scarring, loss of conjunctiva, and adhesions are the causes. When we consider the operative procedures available for its correction we can see that they constitute a territory in which many attempts have been made and many failures have occurred.

Of all the available methods of operation at the present time, only those of Esser (modified) and Czapody are worthy of consideration. Both these methods have the same sound basic theory, but both have to a greater or lesser degree the same basic defect.

1. In Esser's method, the force which should work against - shrinkage comes not from within outwards (as it should), but from without inwards, i.e., by closing the lids when the cavity is filled with "Stent," or other material. In Czapody's method the force is from within outwards, but in a linear direction (see Figs. 6 and 7 ).

2. The method of Esser does nothing and that of Czapody does very little to overcome the retraction due to shrinkage of the graft and adhesions which occur after covering the newly produced bare area. (Czapody makes several small incisions at the base of his covering graft.)

A method has been devised which is not subject to the faults of the above operations and is here described. A modified technique and a new design of cavity-dilator (see Figs. 8 and 9) are employed.

Details of operation (Note: This description applies to a lower lid only, but can be equally applied to an upper lid or both lids).

Stage 1.-After a large canthotomy to the orbital margin, three stitches are inserted into the lower lid margin, and with these the lid is pulled down (see Fig. 1). Two or three millimetres from the lid margin and parallel to it the conjunctiva is cut. It 
is undermined to the equator of the cavity and lifted upwards (Fig. 2).

Stage 2.-Skin is taken either from the arm or from bẹhind the ear of the same shape, but one-third larger than the newly produced raw area in the socket. The graft is prepared according

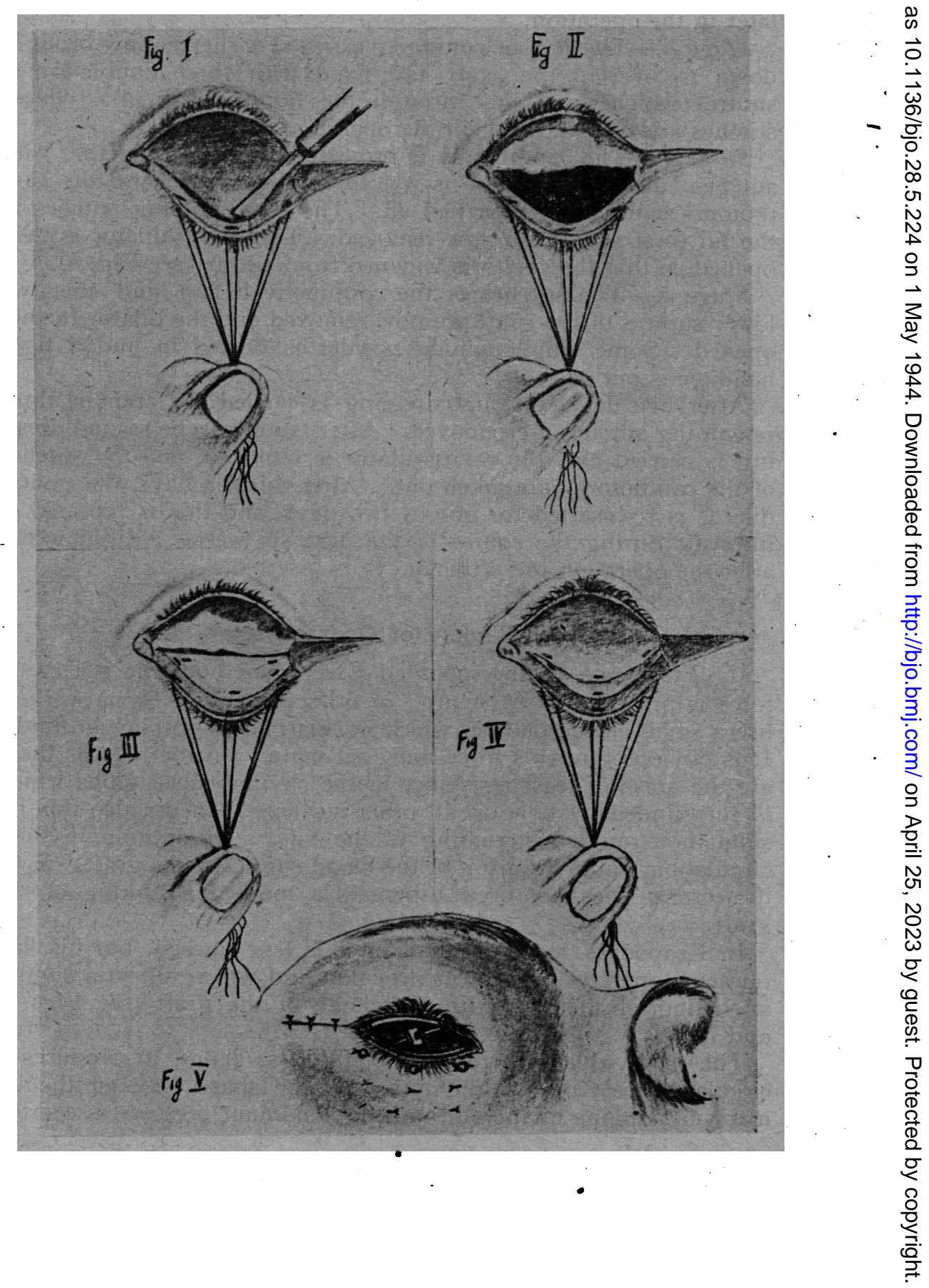


to the method of Le Fort-Wolfe (removal of fat and subcutaneous tissue). Careful haemostasis is essential, and the bare area is dusted with sulphonamide powder before the graft is applied. The graft is then neatly placed on the prepared area and is fixed to the lid by five double-armed sutures which come outwards through the lid (see Fig. 3). The two lower stitches will be removed later in the operation.

Stage 3.-The flap of conjunctiva raised earlier is now brought down to overlap the graft and fixed with three double-armed sutures which come out through the lid (see Fig. 4). These stitches are removed later in the operation.

Stage 4.-The canthotomy is provisionally drawn together with stitches, the cavity-dilator is placed in the cavity, and the canthotomy sutures are then tied off. The three holding stitches in the lid (first stage) are now removed. The cavity-dilator is then opened so that the cavity is widened from within (see Fig. 5).

Stage 5.-The stitches of the conjunctival flap and the two lower sutures of the graft are now removed and the dilator further opened. Some sulphonamide powder is dusted in and a light bandage is put on.

After five days, the first dressing is carried out and the three remaining stitches are removed. After ten days, the second dressing is carried out, the cavity-dilator is removed, and the stitches of the canthotomy are taken out. After thirteen days, the cavitydilator is re-inserted for one or two days, and this is repeated at interrvals during the course of the next six weeks. Eight weeks after the operation the artificial eye is inserted.

\section{Theory of Operation}

1. Pressure.-In the modified Esser's method, the stretching force is provided by "Stent " or other material. Some workers use a small elastic balloon which is enlarged by forcing in fluids. It is obvious that this force must act mainly on the lids, as these are the areas of least resistance in the circumscribed globe which is surrounded by bone at all other surfaces. In practice this results in a marked stretching of the lids, a diminution in their circulation, and a lowering of the blood supply of the graft. Even if necrosis does not occur, there is a marked shrinking of the graft.

In Czapody's method this danger is less marked, but his flap retractor operates in a linear direction and will result in a similar stretching of the lids with shrinkage of the graft (see Figs. 6 and 7).

The cavity-dilator here described (Figs. 8 and 9) produces a circular force from within outwards, the space between the lid margins remains unaltered, and the maximum pressure is exerted 
'OPERATION FOR SHRUNKEN SOCKET

CZAPODY'S FLAP-RE'TRACTOR SHOWN ACTING ON ORBIT IN SECTION
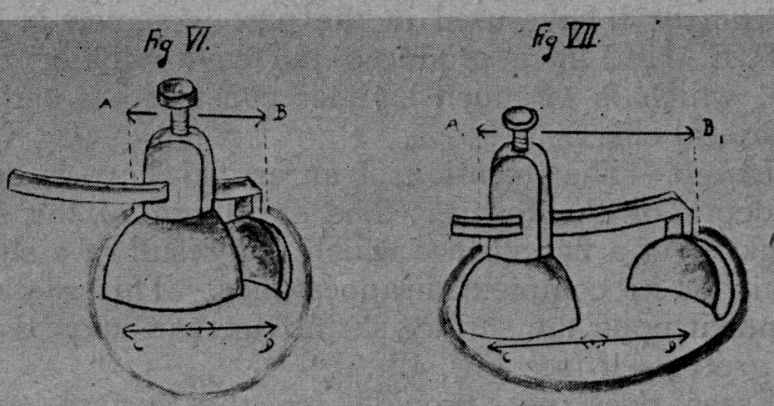

AB: SPACE BETWEEN THE LID-MARGINS

CD: DIRECTION OF DISTENSION LINEAR

CAVITY - DILATOR

SHOWN ACTING ON ORBIT IN SECTION
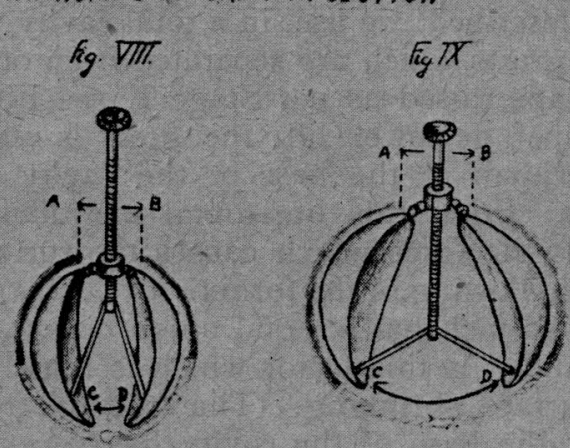

AB: SPACE BETWEEN THE LID-MARGINS

CD. DIRECTION OF DISTENSION CIRCULAR

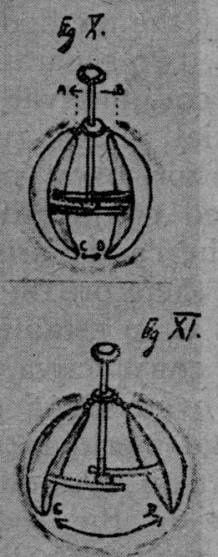

$F_{i g}$ XII

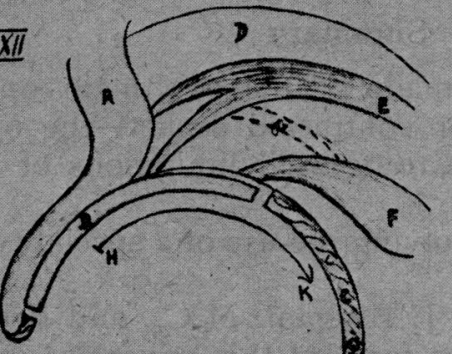

A LIDS

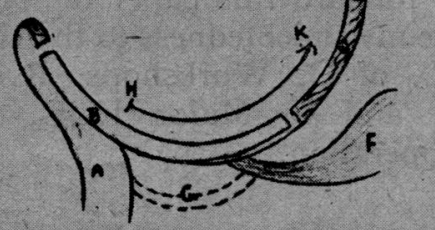

C CONJUNCTIVA

f fasciatarso-orbitalis

E LEVATOR

F Recrus SUP. I INF

6 CONNECTIONS to TIE LIDS

H-K DIRECTION OF

CONTRATTION

olinear meridian 
well within the socket with diminishing force along the retractor blades towards the lid margins. The stretching of the socket is obtained without undue pressure on the lids.

The instrument $I$ have used in the past is shown in Figs. 10 and 11. R.E.M.E. have produced the cavity-dilator shown in this article, which is of much simpler construction and has the same mechanical effect.

2. Shrinkage. - The retention of an artificial eye is dependent upon the depth of the fornix. The shrinking of the sac itself is the shrinking of a flat surface which will result in a shallowing of the fornix or its complete disappearance. This shallowing is more dependent upon the surface shrinking than upon the shrinking of the graft itself (see Fig. 12).

While Esser does not provide for the surface shrinking, Czapody uses fine cuts in the base of the transplant to overcome it.

Natural shrinking of a graft can be overcome by stretching, but a major problem presents itself when the shrinking of a flat surface is involved.

By the method described, we use, in a total cavity plastic operation, two separate grafts which are separated from one another by the conjunctival flaps raised as per Stage 1 (see Fig. 12). In a partial plastic (upper or lower lid) the graft is separated from the horizontal meridian at the base of the cavity by the same raised conjunctiva. From this horizontal meridian at the base of the cavity arises the force which causes the surface shrinking and therefore the shallowing of the fornix.

It is an established fact. that no total union occurs between skin and conjunctiva, and it is this factor which is largely responsible for overcoming surface shrinking. The traction from the horizontal meridian at the base of the cavity has very little, if any, effect on the new graft and can have but little tendency to reproduce in the socket the shrinking whith these procedures are designed to abolish.

\section{Summary}

1. Mention has been made of the two main operative procedures in present use for contracted socket-the operations of Esser and Czapody. The recognised limitations of these operations are indicated.

2. A new operation involving the use of a special type of socket dilator is described.

I wish to thank Colonel J. Biggam, M.C., and Brigadier G. I. Scott for permission to put forward this paper for publication.

I also wish to acknowledge my indebtedness-to the Commanding Officer and 'Staff of 319 L. of C. Workshops, R.E.M.E., for making the cavity-dilator, and to Major I. C. Michaelson, R.A.M.C., for his kind co-operation. 